\title{
One million new patients missing out on dental services, warns BDA
}

\author{
Around a million \\ new patients tried \\ unsuccessfully to \\ access routine NHS \\ dental services in \\ the past two years, \\ according to a new \\ analysis of official \\ health data carried \\ out by the BDA. \\ The trade union \\ says the discovery \\ comes at a perilous \\ time shown by other \\ work it has done \\ that suggests $59 \%$ of \\ dental practitioners \\ based in England \\ are now planning to
} scale down or leave

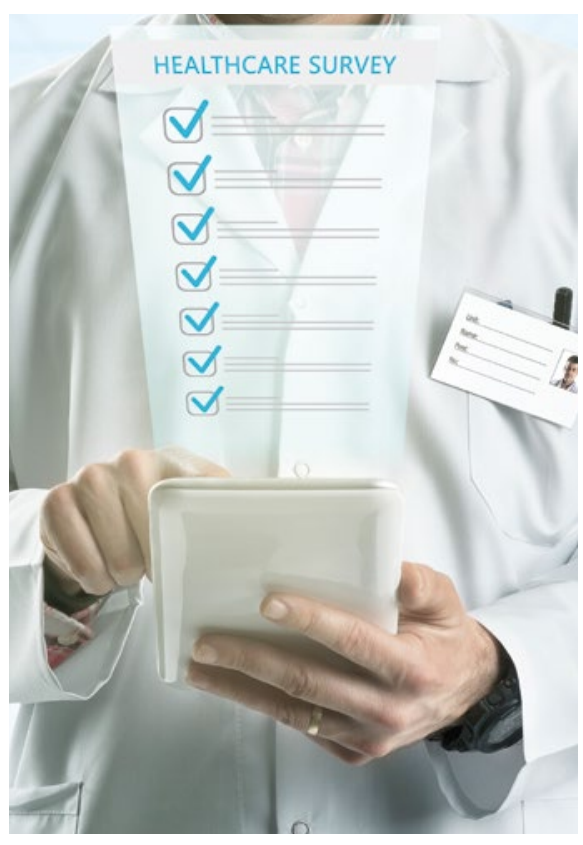

or leave NHS work entirely in the next five years. The phrase 'leaving the NHS' included those people intending to increase their proportion of private work, to leave the UK to work overseas, to retire or to leave dentistry to work in a completely different sector in the next five years.

Those with higher NHS commitments were the most likely to leave as the survey found that $67 \%$ of

NHS work entirely in the next five years.

These disturbing trends were identified by the BDA analysis of government data published in August of last year. That data - the GP Patient Survey $2018^{1}$ - gathered responses from 758,000 patients and of those, just under three fifths (59\%) tried to get an NHS dental appointment in the last two years.

Based on feedback from 369,474 patients, almost a quarter of new patients (estimated at more than one million in total) not currently on the books with an NHS dentist had tried and failed to secure an NHS appointment. The BDA modelled this data with adult population figures from the Office for National Statistics.

The new analysis also showed there were access problems across every English region, with more than $40 \%$ of these irregular attenders missing out in parts of Norfolk, Derbyshire, West Yorkshire and Cornwall, reaching more than $60 \%$ in parts of Lincolnshire.

The union also released some findings from its not yet published 2018 BDA surveys of general dental practitioners and specialist practitioners for which fieldwork was carried out between 8 June and 10 August 2018.

From the 1,129 valid questionnaires completed and returned, the BDA survey showed that $59 \%$ of practitioners based in England were now planning to scale down dentists seeing more than $75 \%$ NHS patients expressed their intentions to move on, falling to $51 \%$ among those doing less NHS work.

The BDA said the government appeared to be unwilling to heed warnings over growing recruitment and retention issues in the service and despite pledges to put prevention and primary care at the heart of the recently published NHS Long Term Plan, no commitments had been made to guarantee the future sustainability of high street dentistry.

BDA Vice Chair Eddie Crouch said: 'High Street NHS dentistry is on the brink, and it's the patients who need us most who risk losing out.

'Across England practices are now unable to fill vacancies, as a system of unforgiving targets pushes talented colleagues out. The result is hundreds of thousands of irregular attenders - many with poor oral health - are falling through the cracks.

'These aren't just patients seeking a regular check-up. They are often people in pain, left without the care they need. Dentists were looking for a lifeline in the recent 10 Year Plan, but were offered little more than a footnote.'

\section{References}

1. NHS England. Summary of the Dental Results from the GP Patient Survey - January to March 2018. 2018. Available at https://www.england.nhs.uk/ statistics/2018/08/09/gpps_dent_x1786_239846/ (accessed February 2018). 